\title{
Transcatheter Aortic Valve Implantation in Bicuspid Aortic Valve with Aortic Stenosis: a Meta-Analysis and Trial Sequential Analysis
}

Jeffrey Shi Kai Chan ${ }^{1,2^{*}}$, MBChB; Sukhdeep Singh ${ }^{2 *}$, MBChB; Peter Eriksen ${ }^{3}$; Lok Him Tsui ${ }^{4}$; Amer Harky ${ }^{5,6^{*}}$, MBChB, MRCS, MSc; for the Cardiovascular Evidence Review Collaboration (CvERC) ${ }^{* *}$

DOI: $10.21470 / 1678-9741-2020-0146$

\begin{abstract}
Objectives: Bicuspid aortic valve (BAV) is an important aetiology of aortic stenosis and the use of transcatheter aortic valve implantation (TAVI) has not been fully explored in this cohort. This systematic review and meta-analysis compared the outcomes of TAVI in stenotic BAV against tricuspid aortic valve (TAV).

Methods: An electronic literature search was performed in PubMed, MEDLINE, EMBASE, and Scopus to identify all studies comparing TAVI in stenotic BAV versus TAV. Only studies comparing TAVI in BAV versus TAV were included, without any limit on the study date. Primary endpoints were 30-day and 1-year mortality, while secondary endpoints were postoperative rates of stroke, acute kidney injury (AKI), and permanent pacemaker (PPM) requirement. A trial sequential analysis (TSA) was performed for all endpoints to understand their significance.

Results: Thirteen studies met the inclusion criteria (917 BAV and
\end{abstract}

3079 TAV patients). The BAV cohort was younger ( $76.8 \pm 7.43$ years vs. 78.5 \pm 7.12 years, $P=0.02$ ), had a higher trans-aortic valve gradient $(P=0.02)$, and larger ascending aortic diameters $(P<0.0001)$. No significant difference was shown for primary (30-day mortality $[P=0.45]$ and 1-year mortality $[P=0.41]$ ) and secondary endpoints (postoperative stroke $[P=0.49], A K I[P=0.14]$, and $P P M$ requirement $[P=0.86])$. The BAV group had a higher rate of significant postoperative aortic regurgitation $(P=0.002)$. TSA showed that there was sufficient evidence to conclude the lack of difference in PPM requirements, and 30-day and 1-year mortality between the two cohorts.

Conclusion: TAVI gives satisfactory outcomes for treating stenotic BAV and should be considered clinically.

Keywords: Valvular Heart Disease. Bicuspid Aortic Valve. Transcatheter Aortic Valve Implantation. Meta-Analysis.

\begin{tabular}{ll}
\hline \multicolumn{2}{l}{ Abbreviations, acronyms \& symbols } \\
\hline AKI & $=$ Acute kidney injury \\
AS & $=$ Aortic stenosis \\
BAV & $=$ Bicuspid aortic valve \\
CI & $=$ Confidence interval \\
PPM & $=$ Permanent pacemaker \\
PRISMA & $=$ Preferred Reporting Items for Systematic Reviews \\
& and Meta-Analyses \\
RR & $=$ Risk ratio \\
SPSS & $=$ Statistical Package for the Social Sciences \\
TAVI & $=$ Transcatheter aortic valve implantation \\
TAV & $=$ Tricuspid aortic valve \\
TSA & $=$ Trial sequential analysis \\
WMD & $=$ Weighted mean differences \\
\hline
\end{tabular}

'Division of Cardiology, Department of Medicine and Therapeutics, Prince of Wales Hospital, Shatin, New Territories, Hong Kong.

2Faculty of Medicine, The Chinese University of Hong Kong, Shatin, New Territories, Hong Kong.

${ }^{3}$ School of Medicine, University of Liverpool, Liverpool, United Kingdom. ${ }^{4} \mathrm{Li}$ Ka Shing Faculty of Medicine, The University of Hong Kong, Hong Kong. ${ }^{5}$ Department of Cardiothoracic Surgery, Liverpool Heart and Chest Hospital. 'Liverpool Centre for Cardiovascular Science, University of Liverpool and Liverpool Heart and Chest Hospital, United Kingdom.

${ }^{* *} \mathrm{~A}$ list of CVERC investigators may be found in Supplementary Material.

* Jeffrey S K Chan and Sukhdeep Singh contributed equally to this study.

\section{INTRODUCTION}

Transcatheter aortic valve implantation (TAVI) is a wellestablished treatment strategy in patients with severe symptomaticaorticstenosis with highsurgical riskforconventional aortic valve replacement ${ }^{[1,2]}$. However, this recommendation was based on clinical trials that excluded patients with bicuspid aortic valve $(\mathrm{BAV})^{[1,2]}$, a common cardiac anomaly present in $0.5-2 \%$ of the general population and associated with the development of aortic stenosis (AS) requiring intervention ${ }^{[3]}$. Generally, patients with BAV have larger annular dimensions, may have variable coronary anatomy, more calcified, bulky and irregular aortic valve leaflets, and altered aortic geometry and blood flow ${ }^{[4,5]}$. These differences can complicate the accurate device delivery

This study was carried out at the Division of Cardiology, Department of Medicine and Therapeutics, Prince of Wales Hospital, Shatin, New Territories, Hong Kong.

\section{Correspondence Address:}

Amer Harky

(iD https://orcid.org/0000-0001-5507-5841

Department of Cardiothoracic Surgery Liverpool Heart and Chest Hospital

Thomas Drive, Liverpool, United Kingdom - Zip code: L14 3PE

E-mail: aaharky@gmail.com 
and apposition of the prosthetic valve during TAVI[6-8]. However, outcomes of TAVI in patients with BAV using new-generation valves have shown promising results, with less paravalvular leak and better postprocedural outcomes than early-generation valves[9-11]. A significant number of centres around the world have also started performing TAVI on stenotic BAV patients. This systematic review and meta-analysis thus sought to thoroughly examine the literature to compare the outcomes of using TAVI in BAV replacement.

\section{METHODS}

This systematic review and meta-analysis was reported according to the Preferred Reporting Items for Systematic Reviews and Meta-Analyses (PRISMA) statement, and was conducted according to The Cochrane Handbook for Systematic Reviews of Interventions ${ }^{[12,13]}$. Electronic searches were performed on PubMed, Scopus, MEDLINE, and EMBASE from their inception up till October 2019 to identify all publications that reported the use of TAVI in patients with BAV. ClinicalTrials.gov was also searched to identify ongoing or unpublished clinical trials. The search string used was "TAVI" OR "valve implantation" OR "percutaneous" AND "bicuspid valve" OR "bicuspid aorta" OR "bicuspid aortic valve" OR "aortic stenosis". Reference lists of identified papers were searched manually to identify other eligible studies.

\section{Inclusion and Exclusion Criteria}

Only studies written in English comparing TAVI in at least five patients with stenotic BAV and tricuspid aortic valve (TAV) were included. Non-comparative studies, studies with less than five patients, and studies including re-do valve-in-valve, tricuspid valve or aortic regurgitation were excluded. Articles were screened by three reviewers (JSKC, PE, LHT). All selected articles were systematically assessed with inclusion and exclusion criteria. Conflicts over inclusion were resolved by an independent reviewer (AH). All included studies were critically appraised using the Newcastle-Ottawa Scale.

\section{Data Extraction and Reported Outcomes}

Summary estimates were manually extracted by three reviewers (SS, PE, LHT). When there were duplicate data, only the most updated data were included. Conflicts over data extraction were resolved by an independent reviewer (JSKC). Primary endpoints included 30-day and 1-year mortality. Secondary endpoints included post-operative stroke, AKI, and need for permanent pacemaker (PPM) implantation. Other baseline, operative and post-operative characteristics were also extracted.

\section{Statistical Analysis}

Risk ratio (RR [95\% confidence interval (CI)]) or weighted mean differences (WMD [95\% CI]) were used as summary measures for primary endpoints. Random effects model was used with the Mantel-Haenszel test or inverse variance analysis, as appropriate. Heterogeneity was assessed by the chi-square test and the $\mathrm{I}^{2}$ statistic, for which values $>0.40$ were considered to imply significant heterogeneity. Sensitivity analysis was performed by removing studies individually from the analysis.

Trial sequential analysis (TSA) was performed on all outcomes using a combination of sample size and event size. O'Brien-Fleming a-spending function was used to adjust the Z-score threshold. Studies with 0 events were handled by adding a constant (1) to both the intervention and control arm. Required information size was estimated from all included studies reporting the analysed variables and incidences calculated from included patients, with a permissible two-sided type 1 error of $5 \%$ and type 2 error of $20 \%$. TSA was performed using the Copenhagen trial unit TSA software version 0.9.5.10 beta.

All P-values were 2-sided, with $P<0.05$ considered significant. Statistical analyses were performed using Review Manager V.5.3 (Copenhagen: The Nordic Cochrane Centre, The Cochrane Collaboration, 2014) and SPSS software version 25.0 (IBM Corp, Armonk, New York, USA).

\section{RESULTS}

Eight studies were deemed eligible for inclusion in this metaanalysis (Figure 1) ${ }^{[14-21]}$. The studies were excluded due to the lack of reports on TAV and BAV cohorts in the same article, in case series with less than 5 patients or in single cohort studies. The articles represented a total of 3996 patients (917 with BAV and 3079 with TAV, Table 1). An electronic search on ClinicalTrials. gov also identified one relevant single-blinded randomized controlled trial. The study is expected to be completed in 2023 (ClinicalTrials.gov identifier: NCT02541877). Results of the critical appraisal by the Newcastle-Ottawa Scale were summarized in Table 2. Each asterisk represents 1 point, with $\geq 7$ out of 9 points unlikely to have a significant risk of bias. The assessment results showed that all studies were unlikely to have a significant risk of bias.

The baseline characteristics were summarized in Table 3. The BAV cohort was significantly younger (WMD -0.89 years $[-1.60$ years, -0.17 year], $P=0.02$ ), and had a higher trans-aortic valve gradient (WMD $1.73 \mathrm{mmHg}[0.31 \mathrm{mmHg}, 3.16 \mathrm{mmHg}], P=0.02$ ), and a larger ascending aortic diameter (WMD $3.92 \mathrm{~mm}[3.02$ $\mathrm{mm}, 4.83 \mathrm{~mm}], P<0.0001)$. All other baseline characteristics were not significantly different.

Operative outcomes were summarized in Table 4 and postoperative outcomes in Table 5. All primary and secondary outcomes were not significantly different and did not have significantly heterogeneous data. These included postoperative stroke (RR 1.22 [0.69, 2.14], $P=0.49 ;\left.\right|^{2}=0$, chi-square=3.29, $P=0.86$; Figure 2), AKI (RR $1.78[0.83,3.85], P=0.14 ; I^{2}=0$, chi-square $=0.39$, $P=0.82$; Figure 3), $P P M$ requirement (RR $0.98[0.82,1.18], P=0.86$; $P^{2}=0$, chi-square $=6.96, P=0.43$; Figure 4), 30-day mortality (RR $1.17[0.78,1.73], P=0.44 ; I^{2}=0$, chi-square $=2.11, P=0.95$; Figure 5), and 1-year mortality (RR $0.89[0.68,1.17], P=0.41 ; 1^{2}=0$, chisquare $=3.90, P=0.42$; Figure 6). However, the BAV cohort had considerable higher rates of significant aortic regurgitation (more than grade 2) postoperatively (RR 1.53 [1.17, 1.99], $P=0.002$ ). All other operative and postoperative outcomes were not significantly different. Sensitivity analysis revealed that the 


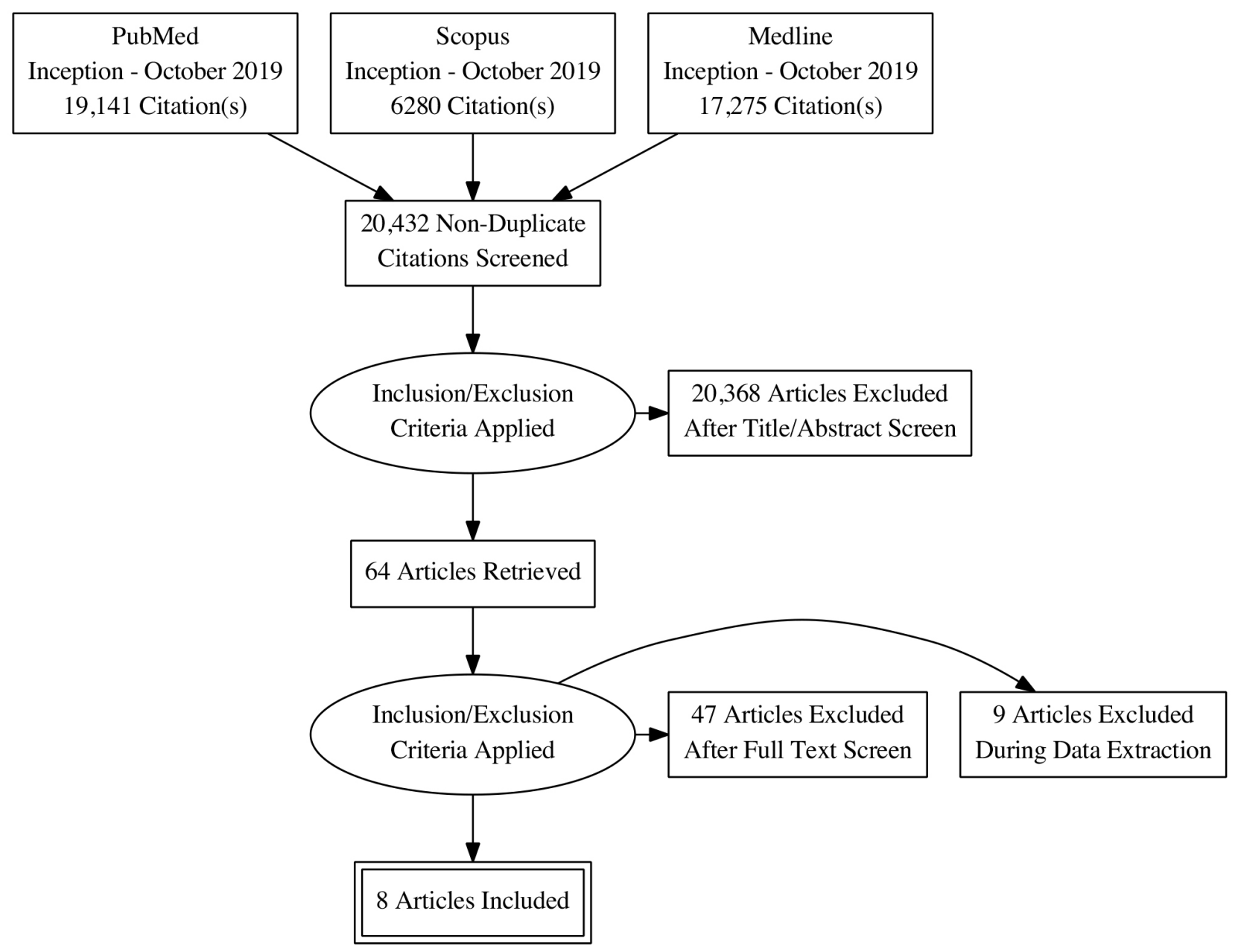

Fig. 1 - Preferred reporting items for systematic reviews (PRISMA) diagram.

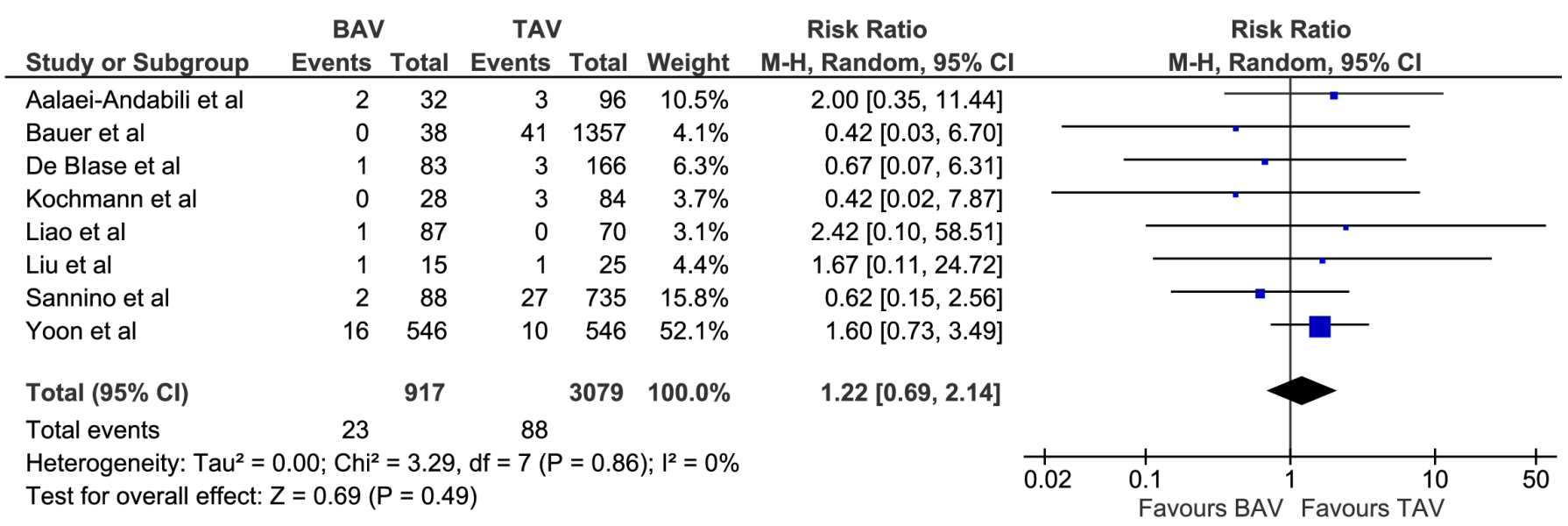

Fig. 2 - Forest plot for postoperative stroke. BAV=bicuspid aortic valve; $C l=$ confidence interval; $M$-H=Mantel-Haenszel; TAV=tricuspid aortic valve. 
Table 1. Summary of all included studies.

\begin{tabular}{|c|c|c|c|c|c|}
\hline Article & $\begin{array}{c}\text { Year of } \\
\text { publication }\end{array}$ & Study type & $\begin{array}{c}\text { BAV } \\
(n=1077)\end{array}$ & $\begin{array}{c}\text { TAV } \\
(n=4165)\end{array}$ & Summary of article \\
\hline Aalei-Andabili et al. ${ }^{[14]}$ & 2018 & $\begin{array}{c}\text { Retrospective } \\
\text { cohort }\end{array}$ & 32 & 96 & $\begin{array}{l}\text { TAVI in patients with BAV provides both } \\
\text { comparable immediate and mid-term } \\
\text { outcomes with TAV and is feasible. }\end{array}$ \\
\hline Bauer et al. ${ }^{[15]}$ & 2014 & $\begin{array}{c}\text { Prospective } \\
\text { cohort }\end{array}$ & 38 & 1357 & $\begin{array}{c}\text { In selected patients, TAVI for BAV can provide } \\
\text { satisfactory results. Risk of relevant AR appears } \\
\text { greater in patients with BAV; however, both 30- } \\
\text { day and 1-year mortalities were not elevated in } \\
\text { relation to TAV. }\end{array}$ \\
\hline De Biase et al. ${ }^{[16]}$ & 2018 & $\begin{array}{c}\text { Prospective } \\
\text { cohort }\end{array}$ & 83 & 166 & $\begin{array}{c}\text { More complex anatomy associated with BAV } \\
\text { at baseline leads to lower device success rates, } \\
\text { but this is not associated with higher } 30 \text {-day } \\
\text { mortalities. }\end{array}$ \\
\hline Kochman et al. ${ }^{[17]}$ & 2014 & $\begin{array}{c}\text { Prospective } \\
\text { cohort }\end{array}$ & 28 & 84 & $\begin{array}{l}\text { Selected high-risk BAV patients can be } \\
\text { successfully treated with TAVI and have similar } \\
\text { outcomes to non-BAV patients. }\end{array}$ \\
\hline Liao et al. ${ }^{[18]}$ & 2018 & $\begin{array}{c}\text { Prospective } \\
\text { cohort }\end{array}$ & 87 & 70 & $\begin{array}{c}\text { TAVI for BAV looks safe and effective, with } \\
\text { comparable bioprosthetic valve functionality } \\
\text { compared to TAV. }\end{array}$ \\
\hline Liu et al. ${ }^{[19]}$ & 2015 & $\begin{array}{c}\text { Prospective } \\
\text { cohort }\end{array}$ & 15 & 25 & $\begin{array}{c}\text { There was no difference between the success of } \\
\text { device, 30-day mortality or the 30-day combined } \\
\text { endpoints between TAVI in BAV and TAV. }\end{array}$ \\
\hline Sannino et al. ${ }^{[20]}$ & 2017 & $\begin{array}{c}\text { Retrospective } \\
\text { cohort }\end{array}$ & 88 & 735 & $\begin{array}{l}\text { TAVI appears safe and effective in BAV, with } \\
\text { no differences in post-procedure mortality, or } \\
\text { 30-day cardiovascular mortality compared to } \\
\text { patients with TAV. }\end{array}$ \\
\hline Yoon et al. ${ }^{[21]}$ & 2017 & $\begin{array}{l}\text { Prospective and } \\
\text { retrospective } \\
\text { cohort }\end{array}$ & 546 & 546 & $\begin{array}{l}\text { TAVI in BAV was associated with similar } \\
\text { prognosis but had lower device success. } \\
\text { Procedural differences occurred with early } \\
\text { devices, but not with new generation ones. }\end{array}$ \\
\hline
\end{tabular}

$A R=$ aortic regurgitation; $B A V=$ bicuspid aortic valve; $T A V=$ tricuspid aortic valve; $T A V I=$ transcatheter aortic valve implantation.

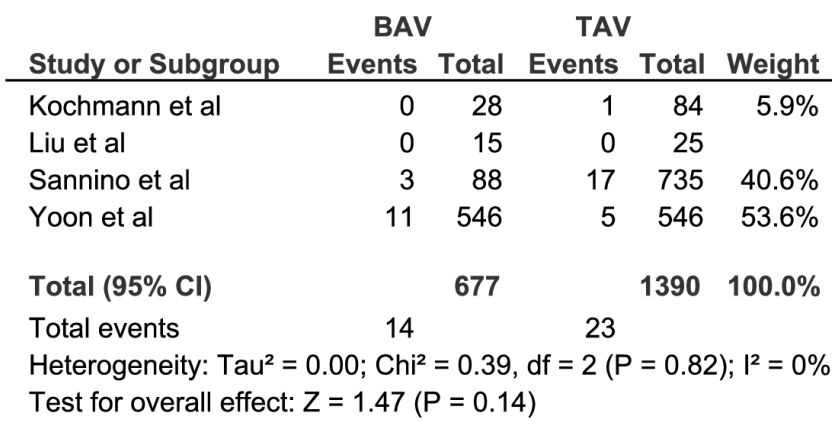

Risk Ratio

M-H, Random, $95 \% \mathrm{Cl}$

$0.98[0.04,23.32]$

Not estimable

$1.47[0.44,4.93]$

$2.20[0.77,6.29]$

$1.78[0.83,3.85]$

Fig. 3 - Forest plot for postoperative acute kidney injury. BAV=bicuspid aortic valve; Cl=confidence interval; M-H=Mantel-Haenszel; TAV=tricuspid aortic valve 
Table 2. Newcastle-Ottawa Scale.

\begin{tabular}{|c|c|c|c|c|c|c|c|c|c|c|}
\hline \multirow[b]{2}{*}{ Author } & \multicolumn{4}{|c|}{ Selection } & \multicolumn{2}{|c|}{ Comparability } & \multicolumn{4}{|c|}{ Outcome } \\
\hline & 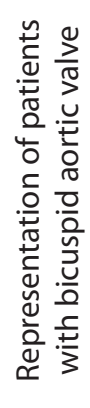 & 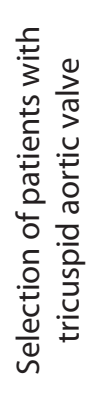 & 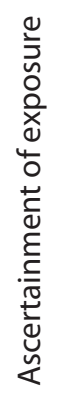 & 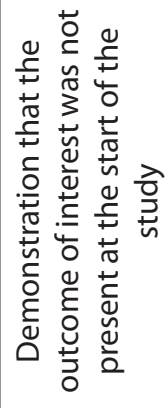 & 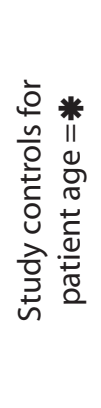 & 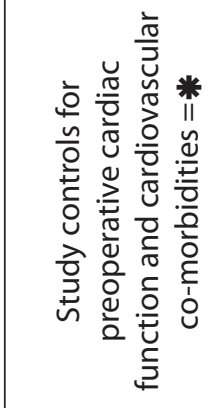 & 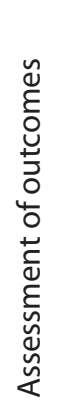 & 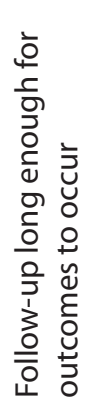 & 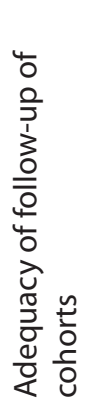 & 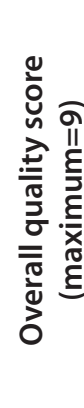 \\
\hline Aalaei-Andabili et al. ${ }^{[14]}$ & * & * & * & * & \multicolumn{2}{|c|}{ ** } & * & & * & 8 \\
\hline Bauer et al.. ${ }^{[15]}$ & * & * & * & * & \multicolumn{2}{|c|}{ ** } & * & & * & 8 \\
\hline De Biase et al. ${ }^{[16]}$ & * & * & * & * & \multicolumn{2}{|c|}{ ** } & * & & * & 8 \\
\hline Kochman et al. ${ }^{[17]}$ & * & * & * & * & \multicolumn{2}{|c|}{ ** } & * & * & * & 9 \\
\hline Liao et al.. ${ }^{[18]}$ & * & * & * & * & \multicolumn{2}{|c|}{ ** } & * & * & * & 9 \\
\hline Liu et al.. ${ }^{[19]}$ & * & * & * & * & \multicolumn{2}{|c|}{ ** } & * & & * & 8 \\
\hline Sannino et al. ${ }^{[20]}$ & * & * & * & * & \multicolumn{2}{|c|}{ ** } & * & * & * & 9 \\
\hline Yoon et al. ${ }^{[21]}$ & * & * & * & * & \multicolumn{2}{|r|}{ ** } & * & * & * & 9 \\
\hline
\end{tabular}

BAV

TAV

Risk Ratio

Study or Subgroup Events Total Events Total Weight $\mathrm{M}-\mathrm{H}, \mathrm{Random}, 95 \% \mathrm{Cl}$

Aalaei-Andabili et al

$\begin{array}{lllll}4 & 32 & 13 & 96 & 3.0 \%\end{array}$

$0.92[0.32,2.63]$

Bauer et al

$475 \quad 1357 \quad 6.1 \%$

$0.45[0.22,0.94]$

De Blase et al

Kochmann et al

1383

$20 \quad 166 \quad 7.9 \%$

Liao et al

$\begin{array}{lllll}8 & 28 & 28 & 84 & 7.6 \%\end{array}$

Liu et al

Sannino et al

Yoon et al

$21 \quad 87$

$20 \quad 70 \quad 12.0 \%$

$\begin{array}{lllll}2 & 15 & 3 & 25 & 1.2 \%\end{array}$

$\begin{array}{lllll}20 & 88 & 133 & 735 & 19.3 \%\end{array}$

$\begin{array}{rrrrr}84 & 546 & 84 & 546 & 42.8 \%\end{array}$

Total $(95 \% \mathrm{Cl})$

917

$3079 \quad 100.0 \%$

Total events 158 776

Heterogeneity: $\mathrm{Tau}^{2}=0.00 ; \mathrm{Chi}^{2}=6.96, \mathrm{df}=7(\mathrm{P}=0.43) ; \mathrm{I}^{2}=0 \%$

Test for overall effect: $Z=0.18(P=0.86)$

$1.30[0.68,2.48]$

$0.86[0.44,1.66]$

$0.84[0.50,1.43]$

$1.11[0.21,5.91]$

$1.26[0.83,1.90]$

$1.00[0.76,1.32]$

$0.98[0.82,1.18]$

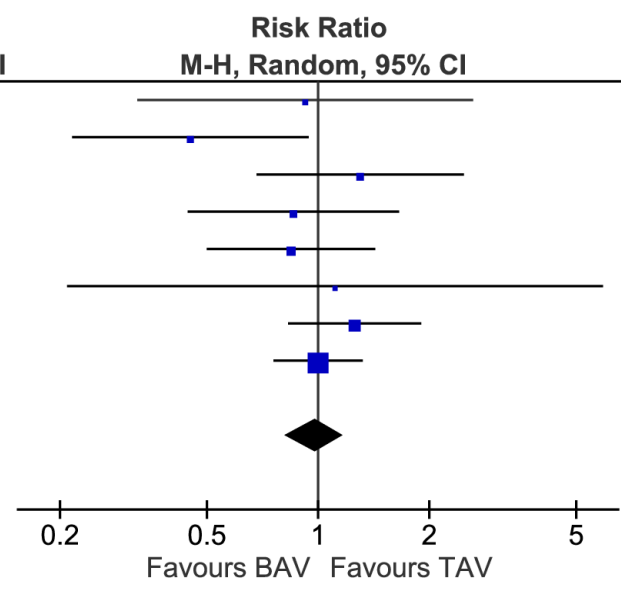

Fig. 4 - Forest plot for postoperative permanent pacemaker requirement. BAV=bicuspid aortic valve; $\mathrm{Cl}=\mathrm{Confidence} \mathrm{interval;} \mathrm{M}$-H=MantelHaenszel; TAV=tricuspid aortic valve

individual removal of studies from the analysis would not affect the statistical significance of the meta-analytical results of any variable.

TSA was performed for 30-day mortality, 1-year mortality, PPM requirement, and postoperative stroke. For 30-day mortality (Figure 7), 1-year mortality (Figure 8) and PPM requirement (Figure 9), the cumulative Z curve of the study data crossed the futility boundary and/or the trial sequential monitoring boundary, indicating that the meta-analysis of these variables was conclusive. However, the cumulative Z curves for postoperative stroke (Figure 10) did not cross any of the boundaries, indicating that meta-analyses of these variables were inconclusive, and further studies were required. TSA 
Table 3. Baseline characteristics of the included patients. The first number is the number of patients with the event or the sample mean value \pm standard deviation of the variable, and the second is the number of patients for whom the event was described. Statistically significant differences were marked with an asterisk $\left(^{*}\right)$.

\begin{tabular}{|c|c|c|c|c|}
\hline Baseline variable & BAV $(n=917)$ & $\operatorname{TAV}(n=3079)$ & OR/WMD [95\% Cl] & $P$-value \\
\hline Age (years $\pm S D$ ) & $76.8 \pm 7.43$ & $78.5 \pm 7.12$ & WMD $-0.89[-1.60,-0.17]$ & $0.02^{*}$ \\
\hline Male (\%) & $562 / 917(61.3)$ & $1554 / 3079(50.5)$ & OR $1.10[0.93,1.31]$ & 0.27 \\
\hline Diabetes mellitus (\%) & 226/917 (24.6) & 980/3079 (31.8) & OR $1.00[0.82,1.21]$ & 0.98 \\
\hline Previous stroke (\%) & $130 / 917(14.2)$ & $357 / 3079$ (11.6) & OR $1.20[0.94,1.54]$ & 0.15 \\
\hline Peripheral arterial disease (\%) & $177 / 834(21.2)$ & $690 / 2913(23.7)$ & OR $0.95[0.67,1.34]$ & 0.76 \\
\hline Hypertension (\%) & $603 / 879(68.6)$ & 1293/1722 (75.1) & OR $0.95[0.78,1.16]$ & 0.61 \\
\hline COPD (\%) & $194 / 834(23.3)$ & $660 / 2913(22.7)$ & OR $1.05[0.84,1.32]$ & 0.67 \\
\hline Ischaemic heart disease (\%) & $175 / 339(51.6)$ & $1472 / 2437(60.4)$ & OR $0.99[0.76,1.29]$ & 0.92 \\
\hline Previous CABG (\%) & $75 / 710(10.6)$ & $340 / 2178(15.6)$ & OR $0.85[0.62,1.17]$ & 0.33 \\
\hline Previous PCI (\%) & 180/797 (22.6) & $709 / 2248(31.5)$ & OR $0.89[0.71,1.11]$ & 0.31 \\
\hline NYHA class III-IV (\%) & $632 / 797(79.3)$ & $1874 / 2248(83.4)$ & OR $1.09[0.86,1.37]$ & 0.48 \\
\hline Atrial fibrillation (\%) & $49 / 273(17.9)$ & 189/996 (19.0) & OR $0.94[0.64,1.38]$ & 0.74 \\
\hline EuroSCORE $(\% \pm S D)$ & $17.4 \pm 10.5$ & $19.4 \pm 12.6$ & WMD -1.15 [-2.63, 0.33] & 0.13 \\
\hline STS score $(\% \pm S D)$ & $6.10 \pm 3.88$ & $6.53 \pm 3.98$ & WMD $0.06[-0.28,0.40]$ & 0.73 \\
\hline Aortic valve area $\left(\mathrm{cm}^{2} \pm \mathrm{SD}\right)$ & $0.629 \pm 0.173$ & $0.660 \pm 0.239$ & WMD $-0.03[-0.06,0.01]$ & 0.11 \\
\hline Trans-aortic valve gradient (mmHg $\pm \mathrm{SD})$ & $52.6 \pm 17.3$ & $49.8 \pm 16.1$ & WMD $1.73[0.31,3.16]$ & $0.02^{*}$ \\
\hline Aortic annular diameter (mm \pm SD) & $23.6 \pm 4.42$ & $24.3 \pm 3.72$ & WMD $-0.23[-1.63,1.17]$ & 0.74 \\
\hline Left ventricular ejection fraction (\% $\%$ SD) & $51.3 \pm 14.2$ & $53.6 \pm 13.0$ & WMD -2.60 [-5.57, 0.37] & 0.09 \\
\hline Ascending aortic diameter $(\mathrm{mm} \pm \mathrm{SD})$ & $38.4 \pm 5.00$ & $34.2 \pm 3.63$ & WMD $3.92[3.02,4.83]$ & $<0.0001^{*}$ \\
\hline
\end{tabular}

$\mathrm{BAV}=$ bicuspid aortic valve; $\mathrm{CABG}=$ coronary artery bypass graft; $\mathrm{Cl}=$ confidence interval; $\mathrm{COPD}=$ chronic obstructive pulmonary disease; NYHA=New York Heart Association; PCI=percutaneous coronary intervention; STS=Society of Thoracic Surgeons; WMD=weighted mean difference

Table 4. Operative outcomes of the included patients. The first number is the number of patients with the event or the sample mean value \pm standard deviation of the variable, and the second is the number of patients for whom the event was described. Statistically significant differences were marked with an asterisk $(*)$.

\begin{tabular}{|c|c|c|c|c|c|}
\hline & & $\operatorname{BAV}(n=917)$ & $\operatorname{TAV}(n=3079)$ & OR $[95 \% \mathrm{Cl}]$ & $P$-value \\
\hline \multirow{4}{*}{$\begin{array}{l}\text { Vascular access } \\
\text { route }\end{array}$} & Transfemoral (\%) & $689 / 829(83.1)$ & 2015/2330 (86.5) & $0.82[0.52,1.28]$ & 0.37 \\
\hline & Transapical (\%) & 22/186 (11.8) & 216/2272 (9.51) & $1.11[0.68,1.80]$ & 0.68 \\
\hline & Transaortic (\%) & $6 / 284(2.11)$ & 48/2463 (1.95) & $1.14[0.42,3.08]$ & 0.80 \\
\hline & Others (\%) & 4/201 (1.99) & $57 / 2297(2.48)$ & $0.91[0.33,2.47]$ & 0.85 \\
\hline \multirow{6}{*}{ Type of valve used } & Sapien XT (\%)X & 175/606 (28.9) & 218/726 (30.0) & $1.01[0.79,1.29]$ & 0.95 \\
\hline & Corevalve (\%) & 256/746 (34.3) & 1391/2178 (63.9) & $1.06[0.62,1.83]$ & 0.82 \\
\hline & Venus A (\%) & $64 / 102$ (62.8) & $60 / 95(63.2)$ & $0.81[0.36,1.83]$ & 0.61 \\
\hline & SAPIEN 3 (\%) & 232/699 (33.2) & $507 / 2165(23.4)$ & $1.38[0.76,2.53]$ & 0.29 \\
\hline & Lotus (\%) & 46/629 (7.31) & $51 / 712(7.16)$ & $0.94[0.62,1.43]$ & 0.78 \\
\hline & EvolutR (\%) & $39 / 629(6.20)$ & $114 / 712(16.4)$ & $0.49[0.06,4.13]$ & 0.51 \\
\hline
\end{tabular}

$\mathrm{BAV}=$ bicuspid aortic valve; $\mathrm{OR}=$ odds ratio; $\mathrm{TAV}=$ tricuspid aortic valve 
Table 5. Postoperative outcomes of the included patients. The first number is the number of patients with the event or the sample mean value \pm standard deviation of the variable, and the second is the number of patients for whom the event was described. Statistically significant differences were marked with an asterisk (*).

\begin{tabular}{|c|c|c|c|c|}
\hline & BAV $(n=917)$ & $\operatorname{TAV}(n=3079)$ & RR/WMD [95\% Cl] & $P$-value \\
\hline Device success (\%) & $712 / 830(85.8)$ & $2812 / 3009(93.5)$ & $\operatorname{RR} 0.96[0.90,1.03]$ & 0.24 \\
\hline Bleeding (\%) & $83 / 764(10.9)$ & $183 / 1460(12.5)$ & RR $1.00[0.72,1.39]$ & 0.98 \\
\hline Conversion to open surgery (\%) & $12 / 746(1.61)$ & $16 / 2178(0.73)$ & RR $2.89[0.53,15.83]$ & 0.22 \\
\hline Vascular complications (\%) & $38 / 802(4.74)$ & $105 / 2817(3.73)$ & RR $1.02[0.66,1.56]$ & 0.94 \\
\hline Trans-aortic valve gradient $(\mathrm{mmHg} \pm \mathrm{SD})$ & $9.74 \pm 5.96$ & $9.78 \pm 5.15$ & WMD $0.09[-0.36,0.54]$ & 0.70 \\
\hline AR more than grade $2(\%)$ & 88/815 (10.8) & $303 / 2984(10.2)$ & $\operatorname{RR} 1.53[1.17,1.99]$ & $0.002^{*}$ \\
\hline Stroke (\%) & $23 / 917(2.51)$ & $88 / 3179(2.77)$ & RR $1.22[0.69,2.14]$ & 0.49 \\
\hline Acute kidney injury (\%) & $14 / 677(2.07)$ & 23/1390 (1.66) & $\operatorname{RR} 1.78[0.83,3.85]$ & 0.14 \\
\hline PPM requirement (\%) & $158 / 917(17.2)$ & $776 / 3079(25.2)$ & $\operatorname{RR} 0.98[0.82,1.18]$ & 0.86 \\
\hline 30-day mortality (\%) & 43/917 (4.69) & $210 / 3079(6.82)$ & RR $1.17[0.78,1.73]$ & 0.45 \\
\hline 1-year mortality (\%) & 76/787 (9.66) & $414 / 2792(14.8)$ & RR $0.89[0.68,1.17]$ & 0.41 \\
\hline
\end{tabular}

$\mathrm{AR}=$ aortic regurgitation; $\mathrm{BAV}=$ bicuspid aortic valve; $\mathrm{OR}=$ odds ratio; $\mathrm{PPM}=$ permanent pacemaker; $\mathrm{RR}=$ risk ratio; $\mathrm{SD}=$ standard deviation; TAV=tricuspid aortic valve; WMD=weighted mean difference

BAV

Study or Subgroup

Aalaei-Andabili et al

Bauer et al

De Blase et al

Kochmann et al

Liao et al

Liu et al

Sannino et al

Yoon et al

Total $(95 \% \mathrm{Cl})$

Total events

Heterogeneity: $\mathrm{Tau}^{2}=0.00 ; \mathrm{Chi}^{2}=2.11, \mathrm{df}=7(\mathrm{P}=0.95) ; \mathrm{I}^{2}=0 \%$

Test for overall effect: $Z=0.76(P=0.45)$
Risk Ratio

M-H, Random, $95 \%$ C

$1.50[0.29,7.81]$

$0.96[0.37,2.45]$

$1.60[0.44,5.80]$

$0.50[0.06,3.98]$

$2.15[0.59,7.79]$

$0.83[0.08,8.43]$

$1.09[0.33,3.55]$

$1.11[0.59,2.08]$

$1.17[0.78,1.73]$
Risk Ratio

M-H, Random, $95 \%$ Cl

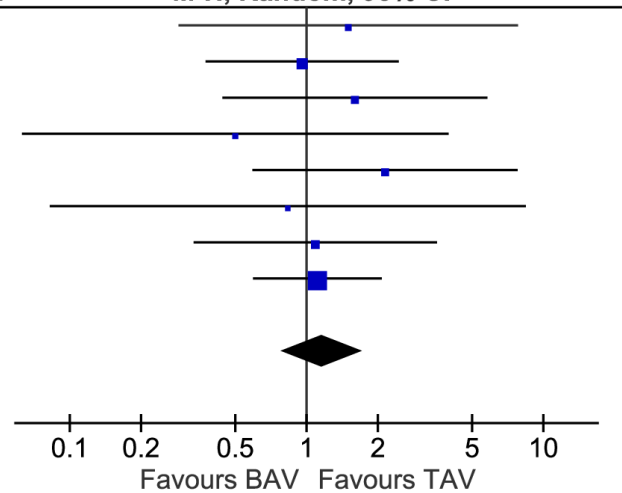

Fig. 5 - Forest plot for postoperative 30-day mortality. BAV=bicuspid aortic valve; $C l=$ confidence interval; $M$-H=Mantel-Haenszel; TAV=tricuspid aortic valve

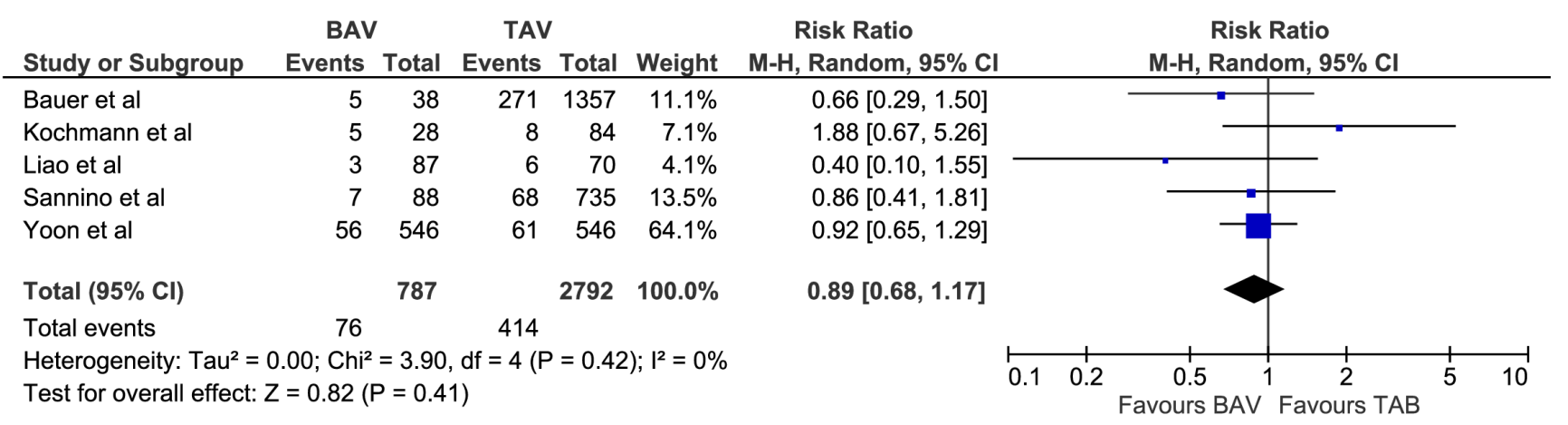

Fig. 6 - Forest plot for postoperative 1-year mortality. BAV=bicuspid aortic valve; $C l=$ confidence interval; $M$-H=Mantel-Haenszel; TAV=tricuspid aortic valve 


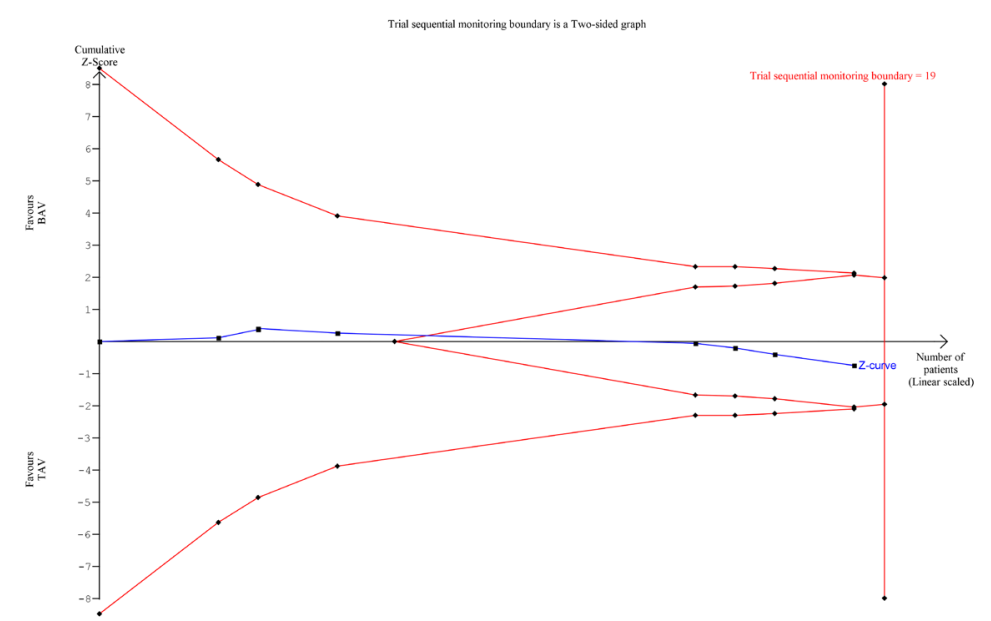

Fig. 7 - Trial sequential analysis diagram for 30-day mortality. BAV=bicuspid aortic valve; TAV=tricuspid aortic valve

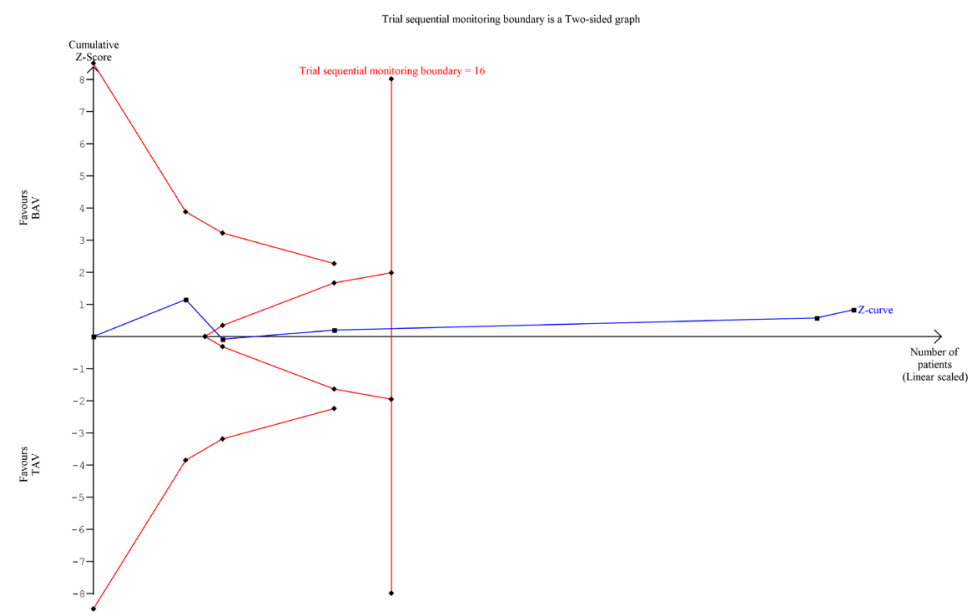

Fig. 8 - Trial sequential analysis diagram for 1-year mortality. BAV=bicuspid aortic valve; TAV=tricuspid aortic valve

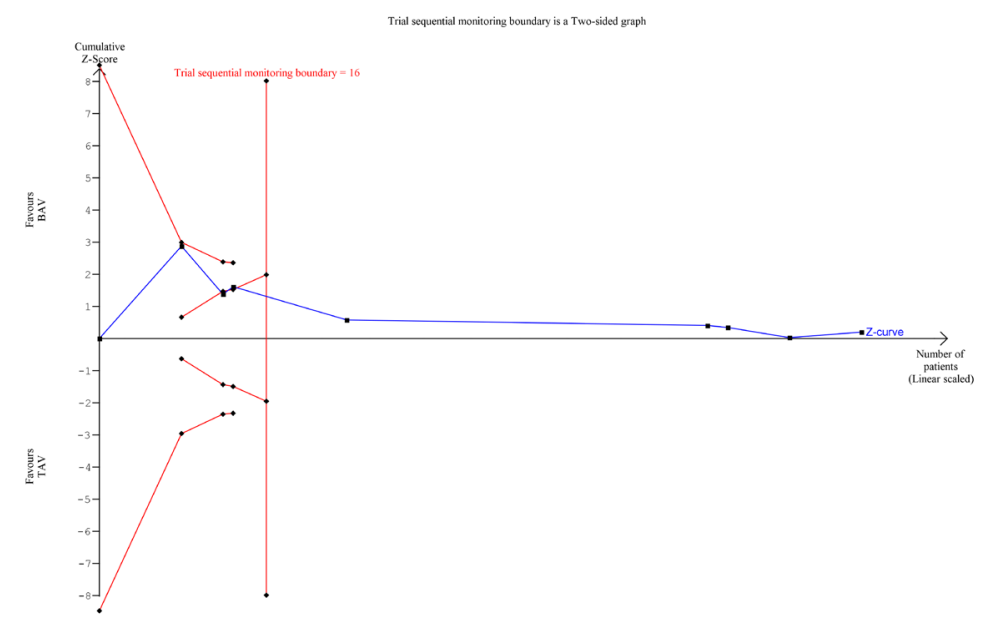

Fig. 9 - Trial sequential analysis diagram for postoperative permanent pacemaker requirement. $B A V=$ bicuspid aortic valve; $T A V=$ tricuspid aortic valve was not possible for AKI due to the small sample and event sizes.

\section{DISCUSSION}

TAVI has not been fully explored in patients with BAV, and the latest guidelines did not fully support the use of TAVI in BAV patients ${ }^{[22,23]}$. We thus evaluated the existing evidence for the safety of TAVI in stenotic BAV compared to that in TAV. In this study, a total of eight articles with 917 stenotic BAV and 3079 stenotic TAV patients were metaanalysed. We showed no significant difference in primary and secondary outcomes, including AKI, PPM requirement, stroke, and 30-day mortality. TSA results confirmed that 30-day and 1-year mortality, as well as PPM requirements, were not significantly different between BAV and TAV, while more evidence was required for stroke. As such, TAVI is largely safe for clinical use in stenotic BAV patients.

However, BAV was associated with a considerable higher rate of significant aortic regurgitation postoperatively $(P=0.002)$. It should be noted that if studies that started recruitment before 2012 were excluded, i.e. Bauer et al. ${ }^{[15]}$, Kochman et al. ${ }^{[17]}$ and Yoon et al. ${ }^{[21]}$, the difference in the rates of significant postoperative aortic regurgitation would become statistically insignificant (RR $1.31[0.67,2.54], P=0.43 ; I^{2}=0$, chisquare $=0.33, P=0.85)$. This reflected that there was a learning curve for TAVI and the inclusion of older, earlier procedures skewed the data-in fact, Yoon et al. ${ }^{[21]}$ included procedures performed as early as 2005. A plot between the year of publication and the rate of significant postoperative aortic regurgitation showed a decreasing trend across the years (Figure 11). The idea of a learning curve for TAVI has been suggested by others and, therefore, having contemporary data is important ${ }^{[24,25]}$.

Previous meta-analyses on the same topic were published by Takagi et al. ${ }^{[26]}$ and Ueshima et al. ${ }^{[27]}$. Our results largely agree with these studies. Nonetheless, to the best of the authors'knowledge, this was the first meta-analysis to utilize TSA in evaluating TAVI in BAV versus TAV ${ }^{[28]}$. TSA builds on the simple fact that the conclusiveness of any evidence increases with the sample size studied, and that the stronger a true effect is, the fewer the number of subjects that need to be studied for the observed effects to be conclusive. TSA results are presented as plots: whenever the Z-score curve (blue line) crosses either the statistical significance boundary (outer oblique boundaries), the futility boundary (inner oblique boundaries), or the trial sequential monitoring boundary (vertical boundary), the results may be considered stable 


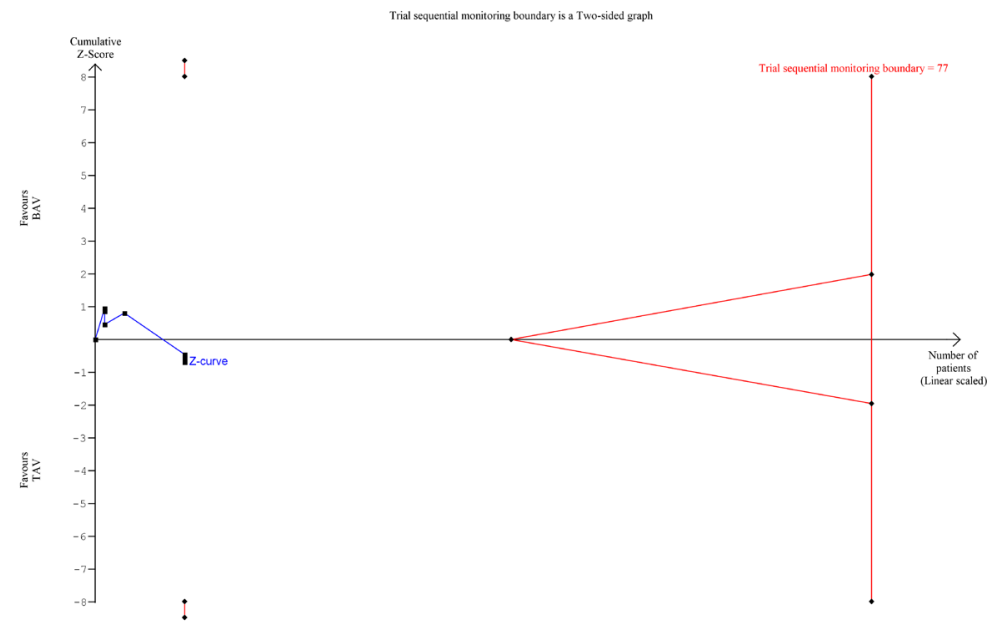

Fig. 10 - Trial sequential analysis diagram for postoperative stroke. BAV=bicuspid aortic valve; TAV=tricuspid aortic valve

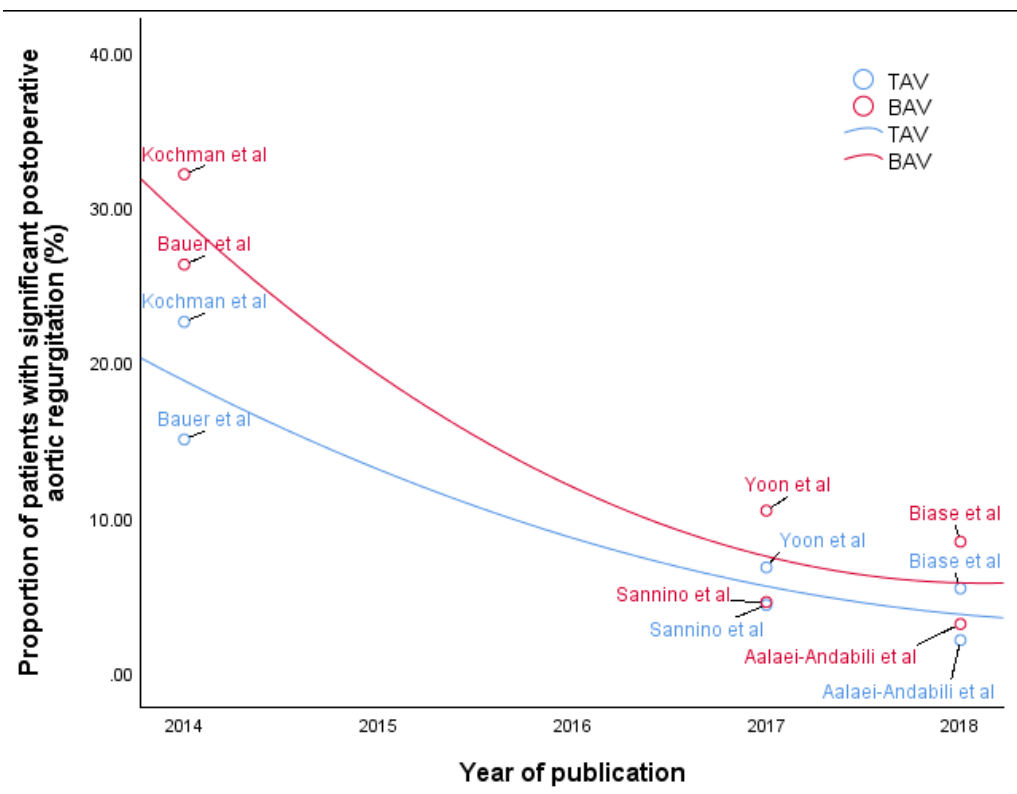

Fig. 11 - Rate of significant postoperative aortic regurgitation in studies according to the year of publication. A decreasing trend is apparent. BAV=bicuspid aortic valve; TAV=tricuspid aortic valve and conclusive. Our results justified further studies designed to evaluate postoperative stroke with adequate power. In fact, with almost 4000 patients included in comparative studies, TSA should be encouraged in subsequent meta-analyses to check if a definitive conclusion has been reached.

This meta-analysis had several limitations. First, it was possible that the manual electronic search had lost articles eligible for inclusion in this study, as well as studies written in non-English languages. Second, late mortality (>1-year follow-up) could not be analysed since only 1 study (Yoon et al. ${ }^{[21]}$ ) followed patients for more than 1 year with adequate data for analysis. These might mean that long-term data of TAVI in TAV were likely not extrapolatable to BAV patients. This is an important consideration for future studies.

Third, subgroup analysis by the BAV subtype was not possible, as none of the included studies reported separate data by BAV subtypes. This has been considered a key parameter that should be assessed in preoperative imaging of BAV patients considered for TAVI. Similarly, subgroup analysis by the type of valve used was not possible due to studies including a mixture of different valves, often from different generations. Reporting outcomes by the type of valve could give a better understanding of whether the benefits of newer generation valves in TAV were applicable in BAV. These should be considered in future studies.

\section{CONCLUSION}

The use of TAVI provides satisfactory outcomes in stenotic BAV patients, largely comparable to those in stenotic TAV patients. Given the current literature, TAVI may be considered clinically for patients with stenotic BAV.

\section{No financial support. No conflict of interest.}

\section{REFERENCES}

1. Leon MB, Smith CR, Mack M, Miller DC, Moses JW, Svensson LG, et al. Transcatheter aortic-valve implantation for aortic stenosis in patients who cannot undergo surgery. N Engl J Med. 2010;363(17):1597-607. doi:10.1056/NEJMoa1008232.

2. Smith CR, Leon MB, Mack MJ, Miller DC, Moses JW, Svensson LG, et al. Transcatheter versus surgical aortic-valve replacement in highrisk patients. N Engl J Med. 2011;364(23):2187-98. doi:10.1056/ NEJMoa1103510.

3. Michelena HI, Desjardins VA, Avierinos JF, Russo A, Nkomo VT, Sundt
TM, et al. Natural history of asymptomatic patients with normally functioning or minimally dysfunctional bicuspid aortic valve in the community. Circulation. 2008;117(21):2776-84. doi:10.1161/ CIRCULATIONAHA.107.740878.

4. Watanabe Y, Chevalier B, Hayashida K, Leong T, Bouvier E, Arai T, et al. Comparison of multislice computed tomography findings between bicuspid and tricuspid aortic valves before and after transcatheter aortic valve implantation. Catheter Cardiovasc Interv. 2015;86(2):32330. doi:10.1002/ccd.25830. 
5. Mahadevia R, Barker AJ, Schnell S, Entezari P, Kansal P, Fedak PW, et al. Bicuspid aortic cusp fusion morphology alters aortic threedimensional outflow patterns, wall shear stress, and expression of aortopathy. Circulation. 2014;129(6):673-82. doi:10.1161/ CIRCULATIONAHA.113.003026.

6. Zegdi R, Lecuyer L, Achouh P, Didier B, Lafont A, Latrémouille C, et al. Increased radial force improves stent deployment in tricuspid but not in bicuspid stenotic native aortic valves. Ann Thorac Surg. 2010;89(3):76872. doi:10.1016/j.athoracsur.2009.12.022.

7. Zhao ZG, Jilaihawi $H$, Feng $Y$, Chen M. Transcatheter aortic valve implantation in bicuspid anatomy. Nat Rev Cardiol. 2015;12(2):123-8. doi:10.1038/nrcardio.2014.161.

8. Himbert D, Pontnau F, Messika-Zeitoun D, Descoutures F, Détaint D, Cueff $C$, et al. Feasibility and outcomes of transcatheter aortic valve implantation in high-risk patients with stenotic bicuspid aortic valves. Am J Cardiol. 2012;110(6):877-83. doi:10.1016/j.amjcard.2012.04.064.

9. Yoon SH, Lefèvre T, Ahn JM, Perlman GY, Dvir D, Latib A, et al. Transcatheter aortic valve replacement with early- and new-generation devices in bicuspid aortic valve stenosis. J Am Coll Cardiol. 2016;68(1 1):1 195-205. doi:10.1016/j.jacc.2016.06.041.

10. Husser O, Pellegrini C, Kessler T, Burgdorf C, Thaller H, Mayr NP, et al. Outcomes after transcatheter aortic valve replacement using a novel balloon-expandable transcatheter heart valve: a single-center experience. JACC Cardiovasc Interv. 2015;8(14):1809-16. doi:10.1016/j. jcin.2015.08.014.

11. Yoon SH, Sharma R, Chakravarty T, Kawamori H, Maeno Y, Miyasaka M, et al. Clinical outcomes and prognostic factors of transcatheter aortic valve implantation in bicuspid aortic valve patients. Ann Cardiothorac Surg. 2017;6(5):463-72. doi:10.21037/acs.2017.09.03.

12. Liberati A, Altman DG, Tetzlaff J, Mulrow C, Gøtzsche PC, loannidis JP, et al. The PRISMA statement for reporting systematic reviews and metaanalyses of studies that evaluate healthcare interventions: explanation and elaboration. BMJ. 2009;339:b2700. doi:10.1136/bmj.b2700.

13. Higgins JPT, Thomas J, Chandler J, Cumpston M, LiT, Page MJ, Welch VA (editors). Cochrane Handbook for Systematic Reviews of Interventions version 6.0 (updated July 2019). Cochrane, 2019. Available from www. training.cochrane.org/handbook.

14. Aalaei-Andabili SH, Beaver TM, Petersen JW, Anderson RD, Karimi A, Thoburn E, et al. Early and midterm outcomes of transcatheter aortic valve replacement in patients with bicuspid aortic valves. J Card Surg. 2018;33(9):489-96. doi:10.1111/jocs.13775.

15. Bauer T, Linke A, Sievert H, Kahlert P, Hambrecht R, Nickenig G, et al. Comparison of the effectiveness of transcatheter aortic valve implantation in patients with stenotic bicuspid versus tricuspid aortic valves (from the German TAVI registry). Am J Cardiol. 2014;113(3):518-21. doi:10.1016/j.amjcard.2013.10.023.

16. De Biase C, Mastrokostopoulos A, Philippart R, Desroche LM, Blanco S, Rehal K, et al. Aortic valve anatomy and outcomes after transcatheter aortic valve implantation in bicuspid aortic valves. Int J Cardiol. 2018;266:56-60. doi:10.1016/j.ijcard.2018.01.018.

17. Kochman J, Huczek Z, Scisło P, Dabrowski M, Chmielak Z, Szymański P, et al. Comparison of one- and 12-month outcomes of transcatheter aortic valve replacement in patients with severely stenotic bicuspid versus tricuspid aortic valves (results from a multicenter registry). Am J Cardiol. 2014;1 14(5):757-62. doi:10.1016/j.amjcard.2014.05.063.

18. Liao YB, Li YJ, Xiong TY, Ou YW, Lv WY, He JL, et al. Comparison of procedural, clinical and valve performance results of transcatheter aortic valve replacement in patients with bicuspid versus tricuspid aortic stenosis. Int J Cardiol. 2018;254:69-74. doi:10.1016/j.ijcard.2017.12.013.

19. Liu XB, Jiang JB, Zhou QJ, Pu ZX, He W, Dong AQ, et al. Evaluation of the safety and efficacy of transcatheter aortic valve implantation in patients

\section{Authors' roles \& responsibilities}

JSKC

Substantial contributions to the conception or design of the work; or the acquisition, analysis, or interpretation of data for the work; drafting the work or revising it critically for important intellectual content; final approval of the version to be published

SS Substantial contributions to the conception or design of the work; or the acquisition, analysis, or interpretation of data for the work; drafting the work or revising it critically for important intellectual content; final approval of the version to be published

PE Substantial contributions to the conception or design of the work; or the acquisition, analysis, or interpretation of data for the work; drafting the work or revising it critically for important intellectual content; final approval of the version to be published

LHT Substantial contributions to the conception or design of the work; or the acquisition, analysis, or interpretation of data for the work; drafting the work or revising it critically for important intellectual content; final approval of the version to be published

$\mathrm{AH}$ Substantial contributions to the conception or design of the work; or the acquisition, analysis, or interpretation of data for the work; drafting the work or revising it critically for important intellectual content; final approval of the version to be published

with a severe stenotic bicuspid aortic valve in a Chinese population. J Zhejiang Univ Sci B. 2015;16(3):208-14. doi:10.1631/jzus.B1500017.

20. Sannino A, Cedars A, Stoler RC, Szerlip M, Mack MJ, Grayburn PA. Comparison of efficacy and safety of transcatheter aortic valve implantation in patients with bicuspid versus tricuspid aortic valves. Am J Cardiol. 2017;120(9):1601-6. doi:10.1016/j.amjcard.2017.07.053.

21. Yoon SH, Bleiziffer S, De Backer O, Delgado V, Arai T, Ziegelmueller J, et al. Outcomes in transcatheter aortic valve replacement for bicuspid versus tricuspid aortic valve stenosis. J Am Coll Cardiol. 2017;69(21):2579-89. doi:10.1016/j.jacc.2017.03.017.

22. Baumgartner H, FalkV, Bax JJ, De Bonis M, Hamm C, Holm PJ, et al. 2017 ESC/EACTS guidelines for the management of valvular heart disease. Eur Heart J. 2017;38(36):2739-91. doi:10.1093/eurheartj/ehx391.

23. Nishimura RA, Otto CM, Bonow RO, Carabello BA, Erwin JP 3rd, Fleisher LA, et al. 2017 AHA/ACC focused update of the 2014 AHA/ACC guideline for the management of patients with valvular heart disease: a report of the American college of cardiology/American heart association task force on clinical practice guidelines. Circulation. 2017;135(25):e1 159-95. doi:10.1161/CIR.0000000000000503.

24. Kaier K, Reinecke H, Schmoor C, Frankenstein L, Vach W, Hehn P, et al. Learning curves among all patients undergoing transcatheter aortic valve implantation in Germany: a retrospective observational study. Int J Cardiol. 2017;235:17-21. doi:10.1016/j.ijcard.2017.02.138

25. Alli OO, Booker JD, Lennon RJ, Greason KL, Rihal CS, Holmes DR Jr. Transcatheter aortic valve implantation: assessing the learning curve. JACC Cardiovasc Interv. 2012;5(1):72-9. doi:10.1016/j.jcin.2011.09.014.

26. Takagi H, Hari Y, Kawai N, Kuno T, Ando T; ALICE (All-Literature Investigation of Cardiovascular Evidence) Group. Meta-analysis of transcatheter aortic valve implantation for bicuspid versus tricuspid aortic valves. J Cardiol. 2019;74(1):40-8. doi:10.1016/j.jjcc.2019.03.018.

27. Ueshima D, Nai Fovino L, Brener SJ, Fabris T, Scotti A, Barioli A, et 
al. Transcatheter aortic valve replacement for bicuspid aortic valve stenosis with first- and new-generation bioprostheses: a systematic review and meta-analysis. Int J Cardiol. 2020;298:76-82. doi:10.1016/j. ijcard.2019.09.003.
28. Yoon SH, Maeno Y, Kawamori H, Miyasaka M, Nomura T, Ochiai T, et al. Diagnosis and outcomes of transcatheter aortic valve implantation in bicuspid aortic valve stenosis. Interv Cardiol. 2018;13(2):62-5. doi:10.15420/icr.2018:8:2.

\section{Supplementary Material}

- Cardiovascular Evidence Review Collaboration (CVERC) investigators

- Jeffrey Shi Kai Chan, Division of Cardiology, Department of Medicine and Therapeutics, Prince of Wales Hospital, Hong Kong; Faculty of Medicine, The Chinese University of Hong Kong, Hong Kong

- Amer Harky, Department of Cardiothoracic Surgery, Liverpool Heart and Chest Hospital, Liverpool, United Kingdom

- Hummad Anwar, University Hospitals of Leicester NHS Trust, Leicester, United Kingdom

- Christiana Bithas, Southport and Ormskirk Hospital NHS Trust, Southport, United Kingdom

- Grace Chaplin, School of Medicine, University of Liverpool, Liverpool, United Kingdom

- Chun Ming Chiu, Brighton and Sussex Medical School, University of Sussex, East Sussex, United Kingdom

- Fiona Choi, School of Medicine, University of Liverpool, Liverpool, United Kingdom

- Dileep Duwa, Department of Cardiothoracic Surgery, Liverpool Heart and Chest Hospital, Liverpool, United Kingdom

- Ka Siu Fan, St George's Medical School, University of London, United Kingdom

- Shahi Ghani, St George's University of London, Tooting, United Kingdom

- Ciarin Grafton-Clarke, School of Life Sciences, University of Leicester, Leicester, United Kingdom
- Shubhi Gupta, School of Medicine, University of Liverpool, Liverpool, United Kingdom

- Kantida Koysombat, School of Medicine, University of Liverpool, Liverpool, United Kingdom

- Ji Yen Ku, School of Medicine, University of Liverpool, Liverpool, United Kingdom

- Ter-Er Kusu-Orkar, Pilgrim Hospital, Boston, United Kingdom

- Jason Lee, School of Medicine, University of Liverpool, Liverpool, United Kingdom

- Beverly MacCarthy-Ofosu, Countess of Chester Hospital, Chester, United Kingdom

- Nina Oguamanam, East Sussex NHS Trust, East Sussex, United Kingdom

- Pratik Rai, School of Medicine, University of Liverpool, Liverpool, United Kingdom

- Siddiq Ur Rehman, Southport and Ormskirk Hospital NHS Trust, Southport, United Kingdom

- Sugeevan Savarimuthu, Broomfield Hospital, Chelmsford, East of England Deanery, United Kingdom

- Sukhdeep Singh, Faculty of Medicine, The Chinese University of Hong Kong, Hong Kong

- Pawel Sokal, School of Medicine, University of Liverpool, Liverpool, United Kingdom

- Wing Yan Elizabeth Wong, Brighton and Sussex Medical School, University of Sussex, East Sussex, United Kingdom

- Sevim Zaim, School of Medicine, University of Liverpool, Liverpool, United Kingdom 